\title{
The Impact of the Educational Potential of School on Successful Development of the Motivation-value Attitude to the Learning Activities of Students
}

\author{
E. Sanina ${ }^{1}$, S. Mitrohina ${ }^{2}$, N. Brunchukova ${ }^{3}$, M. Mozgovaya ${ }^{4, *}$, L. Zenkova ${ }^{1}$ \\ ${ }^{1}$ Department of Integrated Security and Physical Culture, Faculty of Supplementary Professional Education, Academy of Public \\ Administration, Moscow, Russian Federation \\ ${ }^{2}$ Department of Pedagogy, Disciplines and Methodics of Primary Education, Faculty of Arts, Social Sciences and Humanities, Tula \\ State Pedagogical University, Tula, Russian Federation \\ ${ }^{3}$ Department of Theory and Methods of Primary Education, Faculty of Psychology and Pedagogy, Smolensk State University, \\ Smolensk, Russian Federation \\ ${ }^{4}$ Department of Mathematics, Physics and Methods of Teaching, Institute of Applied Informatics, Mathematics and Physics, Armavir \\ State Pedagogical University, Armavir, Russian Federation
}

Received June 14, 2020; Revised August 28, 2020; Accepted September 11, 2020

\section{Cite This Paper in the following Citation Styles}

(a): [1] E. Sanina, S. Mitrohina, N. Brunchukova, M. Mozgovaya, L. Zenkova, "The Impact of the Educational Potential of School on Successful Development of the Motivation-value Attitude to the Learning Activities of Students, "Universal Journal of Educational Research, Vol. 8, No. 10, pp. 5072-5080, 2020. DOI: 10.13189/ujer.2020.081107.

(b): E. Sanina, S. Mitrohina, N. Brunchukova, M. Mozgovaya, L. Zenkova (2020). The Impact of the Educational Potential of School on Successful Development of the Motivation-value Attitude to the Learning Activities of Students. Universal Journal of Educational Research, 8(10), 5072-5080. DOI: 10.13189/ujer.2020.081107.

Copyright $\mathrm{C} 2020$ by authors, all rights reserved. Authors agree that this article remains permanently open access under the terms of the Creative Commons Attribution License 4.0 International License

\begin{abstract}
An analysis of the state of education at school leads to the conclusion that, in the secondary school age, the individual enters a new period of development and the definition of personal values changes. The psychological characteristics of students of this school age make it more urgent to develop the motivation and value of students of secondary school age in their educational activities. In order to achieve this goal, it is necessary to seek and explore conditions that encourage motivation to maintain interest in the cognitive activities of students. The article at the theoretical and empirical level proves that the level of development of motivation and cognitive activity depends on the conditions of education and upbringing defined pedagogical conditions that have the greatest impact on these personal characteristics. The authors identified the following conditions: training using the research method, based on the leading type of activity, taking into account the personal interests of students, building individual educational routes, by filling them with non-formal education funds as part of extra-time activities. These studies make a theoretical contribution to pedagogical
\end{abstract}

science. The validity of the provisions is also proved by empirical research (questionnaires, observations, testing). The experimental study also applied mathematical methods to the results of the experiment (of variation, Whitney U-test). The results obtained by the authors can be useful for further research into the development of motivational and value attitude to cognitive activity of secondary school students in a digital educational environment.

Keywords Characteristics of Adolescence, Education of the Personality, Motivation to Training in Mathematics, Pedagogical Conditions

\section{Introduction}

In the State programme «National project «Education»»», approved in 2018, one of the basic provisions is accepted that the development of the personality is ensured through active educational and cognitive activity of the students. 
One of the objectives of the special programme for the development of education is to create conditions that ensure the development of the motivation and abilities of children and young people in knowledge, creativity, work and sports, and the development of an active civic attitude and a culture of a healthy lifestyle.

Analysis of the educational process in school allows us to infer that a person of secondary school age is entering a new period of development, and there is a change in the definition of personally significant values and the system of value judgments. In this period, moral ideals are not sustainable. The problem of educating students' motivational and value attitude to training and learning activity actualizes the psychological features of secondary school age students. To solve this problem, it is vital to seek and study the conditions affecting the stimulation of motives in supporting interest in the learning activity of students.

At the current stage of the development of pedagogical science, you can find a large number of descriptions of the reasons that have an impact on the decline in the level of educational motivation in school. Each of the researchers explains the phenomenon of falling motivation from one or more psychological and pedagogical positions. This is primarily related to the nature of the education system, puberty and gender principle in training. There is an explanation for the fall in the level of educational motivation from the position of the result of changes in the leading activity, as well as in terms of the value of education in a certain historical period. In modern pedagogy, the doctrine of learning motivation is the most controversial area in psycho-pedagogical science. The purpose of the study arises from the need to develop methods and techniques for forming the motivational and value attitude of secondary school age students to teaching and learning activities.

\section{Methodology}

The problem of motivating and valuing attitude to learning activity was considered in the researches of Russian scientists, such as E. V. Bondarevskaya, V. V. Serikov, V. A. Karakovskiy, N. E. Shchurkova, G. I. Shchukina etc. Theoretical analysis of psychological and pedagogical literature on the problem of research, practical experience, observation of the educational process, allowed to identify the contradiction between readiness to the autonomous goal setting, self-identification and solution of personal problems of secondary school age students and lower level of motivation, and often the manifestation of the negative attitude of students to the school in general and the loss of value of teaching in particular. This determines the problem of research, so it is in this period is formed the future orientation of the individual and its value sphere.

The main qualitative indicators of the productivity of the educational process at school are students' critical decision-making and interpersonal communication in teaching activity. Exactly, the quality of education is considered as an indicator that synthesizes all stages of personal development, conditions and results of the educational process, and as an educational institution's performance, which main products are graduates of high quality. The quality of education is a characteristic of the education system that reflects the degree of compliance of the actual achieved educational outcomes, the conditions of the educational process which meet the regulatory, social and personal expectations.

The period of personal maturity is characterized by the desire for self-realization. So the formation of a motivational and value attitude to training and learning activities is the basis for the development of students' personality and the foundation for the formation of conditions for self-realization. This raises the question of what methods and forms of working with children in this age group can best unlock their potential for learning and learning?

Since the subject matter is multidisciplinary and has not been developed in a strictly didactic context before, it should be based on the results of a number of related studies. As a result, the process of building value-based learners has a special role. These include aspirations, motives, motivations, attitudes, interests, needs, desires, vital goals aimed at the most important human values.

It is important to focus on three points. The formation of value orientations should:

1. respond to the development of modern society;

2. be carried out purposefully, systematically, continuously, in all classes and extracurricular activities;

3. to be ahead-of-the-line, in other words, aim for tomorrow.

For clarification, it should be noted that the value orientation is mainly seen as a system of binary relationships of establishment and value, need and value, motive and value, etc.. Value is included in any pair, so it is a system-forming element.

In the philosophical aspect, value orientations are considered as the most important event elements of the internal structure of the individual, fixed by the life experience of the individual, the totality of his experiences (O.G. Drobnitskiy, V.P. Tugarinov, S.F. Anisimov, A.I. Titarenko etc.).

Sociologically, values are defined as an individual's orientation to certain or other social values and ideals that are relevant to both society and the individual (M. Weber, V.T. Lisovskiy, L.A. Verbitskaya, T.N. Malkovskaya, etc.).

In pedagogy, value orientations are determined by a subjective attitude to the objective values of society, expressed in their awareness and experience as needs that motivate real behavior and program the future. The process 
of learning values is the ascension of the individual to universal human values and ideals (E.V. Bondarevskaya, V.V. Serikov, V.A. Karakovskiy, A.I. Shemshurina, N.E. Schurkova, etc.). The subject level implies the development of subject values. The new educational standards state that programs should contain «a description of the values of the content of the subject». Each subject has leading values that teachers can use to guide them. For example, in history classes, people are introduced to such values as «memory», «patriotism», «Fatherland» and others. In gym classes there is an introduction to such concepts as «health», «will», «force» and others. In biology classes people are introduced to such values as «life», «nature», «healthy lifestyle» and so on. At the same time the most important values on different subjects coincide and intersect. This is done spontaneously. But in order to create a full-fledged educational space of the school, it is necessary that this happens consciously, with the participation of all school teachers. What values do work in all the lessons? These are, for example, such values as «good», «truth» and «beauty».

The personal level implies enriching of individual values at the expense of basic and subject values. The formation of value orientations ultimately implies the formation of a common culture of the student, including ethical, aesthetic, intellectual, physical, environmental and other cultures. Integrative mechanisms provide an organic relationship between individual cultures. The latter ones include core competencies, cross-cutting concepts and universal human values.

So, value orientations are a complex social and psychology and pedagogy phenomenon that characterizes the orientation and content of individual activity, which defines the general approach of the individual to peace, to himself, giving meaning and direction to education, to self-improvement, behavior, actions and things. Based on this, we can say that the problem of forming a motivational-value approach to training and learning activity stands at the same level as the most important and basic tasks of education.

Kurt Levin plays a leading role in developing a method for experimentally studying the motivational component. He was the first who proposed the ratio «expectation and value» as a model. This model of determining the level of motivation formation has become the basic one in the research of other prominent western scientists in the theory of achievement motivation (J. W. Atkinson [1], D. McClelland [2], H. Heckhausen [3], R. L. Doernberg and others)

L. Festinger studied the process of motivation in the process of learning activity. Based on the analysis of the obtained data, he developed the theory of cognitive dissonance, which had a great influence on the development of the theory of motivation in general and the theory of educational motivation in particular [4]. In the national pedagogy G.I. Shchukina investigated the influence of methods used in training on the formation and activation of learning activity in general [5].

The issue of value orientations is of interest not only from the point of view of social science and philosophical knowledge. Values are inextricably linked to education. Education and formation of a motivational-value attitude to training and learning activity were considered by scientists from different points of view. But in all the studies there's a generalizing element. It consists in studying of motivation and value orientation according to the age of the period. The manifestation of these personal formations occurs in different ways, at each age. And the specificity of motives and values should be related to the periodization of each age period of the student [6].

Particular interest to us represents the average school age, since this period in domestic and foreign pedagogy is little studied. Age $11-15$ is characterized by a profound transformation of the whole body and is a transition from childhood to adolescence. Changes that occur at this stage are determined by the restructuring of the entire body. The motivational-value component of the student's personal sphere, if we consider it from the standpoint of the structural scheme, consists of two complementary and mutually developing components: motivational and value-based. At the intersection of psychological and pedagogical perceptions of these personal entities, it is necessary to understand how and with what dominance in time one of these entities is leading in the formation of a motivational and value component as a whole. With the transformation of all systems of the body, we can observe changes in attention, thinking and creative development. The possibility of self-expression and self-realization becomes especially important for a teenager at this age. There is a moral conflict between beliefs on the one hand and actions and behavior on the other. Ideals of morality, as well as the structure of value judgments, are unstable and questionable. The motivational sphere is undergoing no less changes. The desire to gain the attention and authority of peers and to gain recognition among equals is becoming a leading motive.

But against this purely personal background, the social component of motivation is beginning to emerge. The individual begins to perceive the common human values by passing them through the prism of his «I». Moral consciousness and life positions begin to be laid at this time period of the formation of the motivational and value sphere.

During the period of restructuring of the moral, voluntariness and emotional sphere, the learning activity and interests of learners change. Despite the fact that the overall motivation for learning decreases, there is an increase in private motivation, namely the emergence of interests in individual subjects. Behavioral responses are also change. During this period, students are prone to disputes and objections, to express their opinions and judgments, to engage in discussion, to prove and to argue 
their point of view. A significant feature of the thinking of a person of secondary school age is person's criticality. During this period of psycho-emotional development, children of this age have a clear argumentative basis in their motives for behavior and teaching. In addition, they can predict the consequences of their decisions. This shows that at this age, a certain internal algorithm for evaluating actions and motives begins to work. This internal mechanism for evaluating actions from the perspective of a promising result is the basis for value orientation [5].

We therefore consider it appropriate to organize the process of developing a motivational and value attitude to educational activities on the basis of leading activities. In this communicative state, when using all the preferences of «communication» as the leading type of activity, the process of activating knowledge and building value orientations will take place in a comfortable environment, without violating the logical sequence in psychological development and training.

The process of development of the motivational - value sphere of students is intensified with the creation of favorable pedagogical conditions. The conditions under which external motivation will be transformed into internal motivation are mandatory for stimulating the motivational sphere [7]. In order to initialize the formation of value orientations are needed «social organized and stimulating activity», in which, «as a result of interaction of the individual with the surrounding world, there will be a conscious transformation of internal and external aspects of life activity» [8].

Empirical research methods included: data collection (questionnaire, observation, testing, conversations), a pedagogical experiment consisting of three stages: ascertaining, searching and shaping; mathematical methods for processing the results of the experiment (coefficient of variation, Whitney U-test, Kruskal-Wallis test Mann) were also applied.

The study was carried out on the basis of state budget educational institution school No. 6 with in-depth study of individual subjects in Naro-Fominsk, Moscow Region. 57 students of grades 5-7 took part in the experiment. All classes with a universal orientation have the same curriculum. The total duration of the pedagogical experiment was 2,5 years. The first stage (September-October 2017 school year) was carried out stating the stage of the experiment, at the second search stage of the experiment we carried out partial testing of pedagogical conditions (November-December 2017 school year) and at the third, forming (December 2017 April 2019) testing of pedagogical conditions and processing of results.

\section{Results}

In the course of theoretical analysis of various sources, studying the best practices of practitioners' teachers and conducting a pedagogical experiment, we have identified a set of conditions in which the process of educating and motivating schoolchildren and value orientations has a positive result.

- The first condition is to increase research activity through the use of interactive learning tools and research methods.

- The second condition is to use the opportunities of an open educational environment.

- The third condition is the individualization of the educational and upbringing process.

- The fourth condition is the activation of creative potential through the use of non-formal education.

All the conditions can be implemented only when all the subjects of the educational process interact. At the same time, it should be noted that interaction from the philosophy point of view is a change in the state or substitution and generation of one object by another in the process of data impact on each other [9]. In pedagogical science, interaction is seen as the main means of coordinated action in the learning process, which is aimed at achieving a certain general result. From the point of personal-oriented pedagogy and humanization of education in general, the style of pedagogical interaction, which is chosen by the teacher for communication with the pupils becomes fundamentally important. Pedagogical interaction can be both constructive and destructive. With the creative nature of interaction, there is a quantitative and qualitative change in the personal formations of the motivational and value spheres of students.

Interactive learning implies a continuous dialogue between all subjects of the educational process. For the most detailed understanding and comprehension of the concept of interactive learning, we think it is advisable to consider the concept of «interactive» in its essence. The term «interactive» derived from «interaction» $[10]$.

Interactive learning tools are part of the toolkit by which the pupil is included in the research method. At the level of training, there is an emergence of private interest, personal attitude to the process of obtaining knowledge. In studying takes place the motivational and value component of personal formations in a process of using the research method as a component of personal-oriented learning based on "conscientious complicity». The method of individual design of educational routes has two properties that we pay attention to in our study. The property of organizing or the ability to maintain the rhythm of the educational process, maintaining its individual orientation, makes it possible to keep the learning process creative. The method of designing individual educational routes allows to create an educational process in which the educational (formal) and extracurricular (non-formal) activities interact with each other. Students are provided with conditions in which they have the opportunity for self-fulfillment, freedom to know their inner world and conditions for the development of 
their personal qualities and individual learning interests [10]. Ensuring the variability of the content of the material studied in the subject, as well as the methods and forms used in training, are most efficiently used in non-formal education. Informal education in the framework of extracurricular activities will allow considering familiar things and issues in a new way. On the other hand, it encourages the interest of students in learning material. They get an emotional boost to learning. If in the non-formal education, in our case it's an extracurricular activity, there is a relationship with the programme material and reliance on the personal experience of the students, the level of learning activity is increased. The acquisition of a meaningful, personal component for the pupil in each specific case makes the teaching activity directed. Changing the nature of the teaching motivation leads to a more pronounced internal learning motive [11].

In a process of education, the most productive will be the creation of such pedagogical conditions in which much attention is paid to the forms of educational activity where the main criterions are independence and variability. In a modern school, the educational function plays a leading role. As before, self-determination, the formation of spirituality, the formation of communicative abilities and value orientations are part of the educational process. Now in education are changing the forms and methods of implementing tasks for the development of these needs. It is possible to influence the development of self-fulfillment, the intensification of learning interest and the development of a motivational and value-based attitude to educational activity by using the resources of supplementary education as a creative educational environment, by enhancing creative capacity. Creating pedagogical conditions that allow students to be included as members of society in economic and social processes is an urgent task of modern education. And in this case, one of the forms of supplementary education, namely non-formal education, seems to be more competitive than other forms of education. So, in conditions of personal-oriented direction, the basic condition of education is the individual development of human beings. In the conditions of personification of education, there is a free choice of the type of activity and its forms. The content has a variable nature and depends on the direction in which the greatest learning interest is manifested. The process of acquiring new knowledge in non-formal education usually takes place outside the institution. The space in which the learning process is carried out is not formalized. Non-formal education is provided by public and educational organizations. Training takes place in the format of round tables, seminars, trainings, etc. But, as in any educational process, when using any of the above forms, there are always specific goals, methods, and as the main result that a document confirming additional education in the framework of informal education. At the same time, non-formal education has an adaptive capacity for changes that occur in the educational process [11]. This is ensured by the fact that non-formal education acts as a personalized form of education, changing the idea of education from the usual «top-down» to the non-standard «bottom-up». Educational principle «bottom-up» is an ideal model of an educational system based on the student's personal interest.

Non-formal education in all its forms has great opportunities for creating conditions for increasing the level of personal interest of students in training and learning activity.

The experimental study was carried out according to the methodology developed by N.T. Badmaeva on the basis of the methodology for studying the motivational sphere of students M.V. Matyukhina, modified taking into account the additional motifs of teaching identified by N.T. Badmaeva (communicative motive and motive of creative self-realization). The technique is designed to diagnose educational motivation of schoolchildren [12]. The test of sample homogeneity in the check and experimental groups is presented in Table 1. The calculation of the differences in the level of educational motivation among these groups is shown in Table 2 . 
Table 1. Test of homogeneity of independent samples

Input Test Results

\begin{tabular}{|c|c|c|c|c|c|c|c|c|c|c|c|}
\hline & \multicolumn{11}{|c|}{ Motives } \\
\hline & $\begin{array}{l}\text { Debt and } \\
\text { responsibility }\end{array}$ & $\begin{array}{l}\text { Self-determination } \\
\text { and } \\
\text { self-improvement }\end{array}$ & Wellbeing & Affiliation & Prestige & $\begin{array}{l}\text { Avoiding } \\
\text { failure }\end{array}$ & $\begin{array}{c}\text { Educational } \\
\text { and } \\
\text { cognitive } \\
\text { (teaching } \\
\text { content) } \\
\end{array}$ & $\begin{array}{c}\text { Educational } \\
\text { and } \\
\text { cognitive } \\
\text { (learning } \\
\text { process) }\end{array}$ & Communicative & $\begin{array}{c}\text { Creative } \\
\text { self-realization }\end{array}$ & $\begin{array}{c}\text { Achieving } \\
\text { success }\end{array}$ \\
\hline Check group (CG) & 24 & 15 & 24 & 24 & 15 & 16 & 25 & 21 & 21 & 15 & 12 \\
\hline Experimental group (EG) & 24 & 16 & 24 & 24 & 16 & 16 & 21 & 20 & 21 & 18 & 18 \\
\hline
\end{tabular}

Table 2. Calculation according to Whitney U-test

\begin{tabular}{|c|c|c|c|c|}
\hline № & $\mathrm{CG}$ & Rank 1 & EG & Rank 2 \\
\hline 1 & 24 & 18.5 & 24 & 18.5 \\
\hline 2 & 15 & 3 & 16 & 6.5 \\
\hline 3 & 24 & 18.5 & 24 & 18.5 \\
\hline 4 & 24 & 18.5 & 24 & 18.5 \\
\hline 5 & 15 & 3 & 16 & 6.5 \\
\hline 6 & 16 & 6.5 & 16 & 6.5 \\
\hline 7 & 25 & 22 & 21 & 13.5 \\
\hline 8 & 21 & 13.5 & 20 & 11 \\
\hline 9 & 21 & 13.5 & 21 & 13.5 \\
\hline 10 & 15 & 3 & 18 & 9.5 \\
\hline 11 & 12 & 1 & 18 & 9.5 \\
\hline Total & & 121 & & 132 \\
\hline
\end{tabular}

$\mathrm{U}_{\text {emp }}=\mathrm{n}_{1} \mathrm{n}_{2}+\left(\mathrm{n}_{\mathrm{x}}\left(\mathrm{n}_{\mathrm{x}}+1\right)\right) / 2-\mathrm{T}_{\mathrm{x}}$, where $\mathrm{n}_{1}=27, \mathrm{n}_{2}=30, \mathrm{n}_{\mathrm{x}}=30, \mathrm{~T}_{\mathrm{x}}=877,5$.

As a result, $\mathrm{U}_{\mathrm{emp}}=55$. Critical values at $\mathrm{p} \leqslant 0.05 \mathrm{U}_{\mathrm{kr}}=34$.

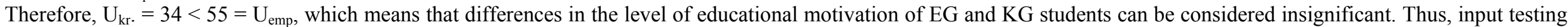

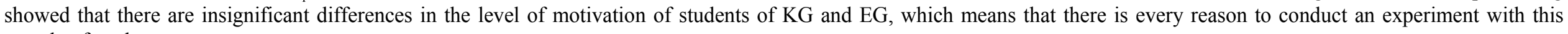
sample of students.

The results of the input and output testing of the check group are shown in Table 3. 
Table 3. Check group (27 people)

\begin{tabular}{|c|c|c|c|c|c|c|c|c|c|c|c|}
\hline & \multicolumn{11}{|c|}{ Motives } \\
\hline & $\begin{array}{l}\text { Duty and } \\
\text { responsibility }\end{array}$ & $\begin{array}{l}\text { Self-determination and } \\
\text { self-improvement }\end{array}$ & Wellbeing & Affiliation & Prestige & $\begin{array}{l}\text { Avoiding } \\
\text { failure }\end{array}$ & $\begin{array}{c}\text { Educational and } \\
\text { cognitive } \\
\text { (teaching content) }\end{array}$ & $\begin{array}{c}\text { Educational and } \\
\text { cognitive } \\
\text { (learning process) }\end{array}$ & Communicative & $\begin{array}{c}\text { Creative } \\
\text { self-realization }\end{array}$ & $\begin{array}{c}\text { Achieving } \\
\text { success }\end{array}$ \\
\hline $\begin{array}{l}\text { Input } \\
\text { testing }\end{array}$ & 24 & 15 & 24 & 24 & 15 & 16 & 25 & 21 & 21 & 15 & 12 \\
\hline $\begin{array}{l}\text { Output } \\
\text { testing }\end{array}$ & 21 & 16 & 25 & 24 & 15 & 17 & 26 & 22 & 21 & 15 & 16 \\
\hline
\end{tabular}

Table 4. Experimental group (30 people)

\begin{tabular}{|c|c|c|c|c|c|c|c|c|c|c|c|}
\hline & \multicolumn{11}{|c|}{ Motives } \\
\hline & $\begin{array}{l}\text { Duty and } \\
\text { responsibility }\end{array}$ & $\begin{array}{l}\text { Self-determination } \\
\text { and } \\
\text { self-improvement }\end{array}$ & Wellbeing & Affiliation & Prestige & $\begin{array}{l}\text { Avoiding } \\
\text { failure }\end{array}$ & $\begin{array}{c}\text { Educational } \\
\text { and } \\
\text { cognitive } \\
\text { (teaching } \\
\text { content) }\end{array}$ & $\begin{array}{c}\text { Educational } \\
\text { and } \\
\text { cognitive } \\
\text { (learning } \\
\text { process) }\end{array}$ & Communicative & $\begin{array}{c}\text { Creative } \\
\text { self-realization }\end{array}$ & $\begin{array}{c}\text { Achieving } \\
\text { success }\end{array}$ \\
\hline Input testing & 24 & 16 & 24 & 24 & 16 & 16 & 21 & 20 & 21 & 18 & 18 \\
\hline Output testing & 27 & 25 & 26 & 26 & 21 & 24 & 29 & 28 & 28 & 26 & 26 \\
\hline
\end{tabular}

The diagram shows that input and output testing data differ slightly (Figure 1). Therefore, in KG there were no significant changes in the motivational sphere of students. The results of the input and output testing of the Experimental group are shown in Table 4. 


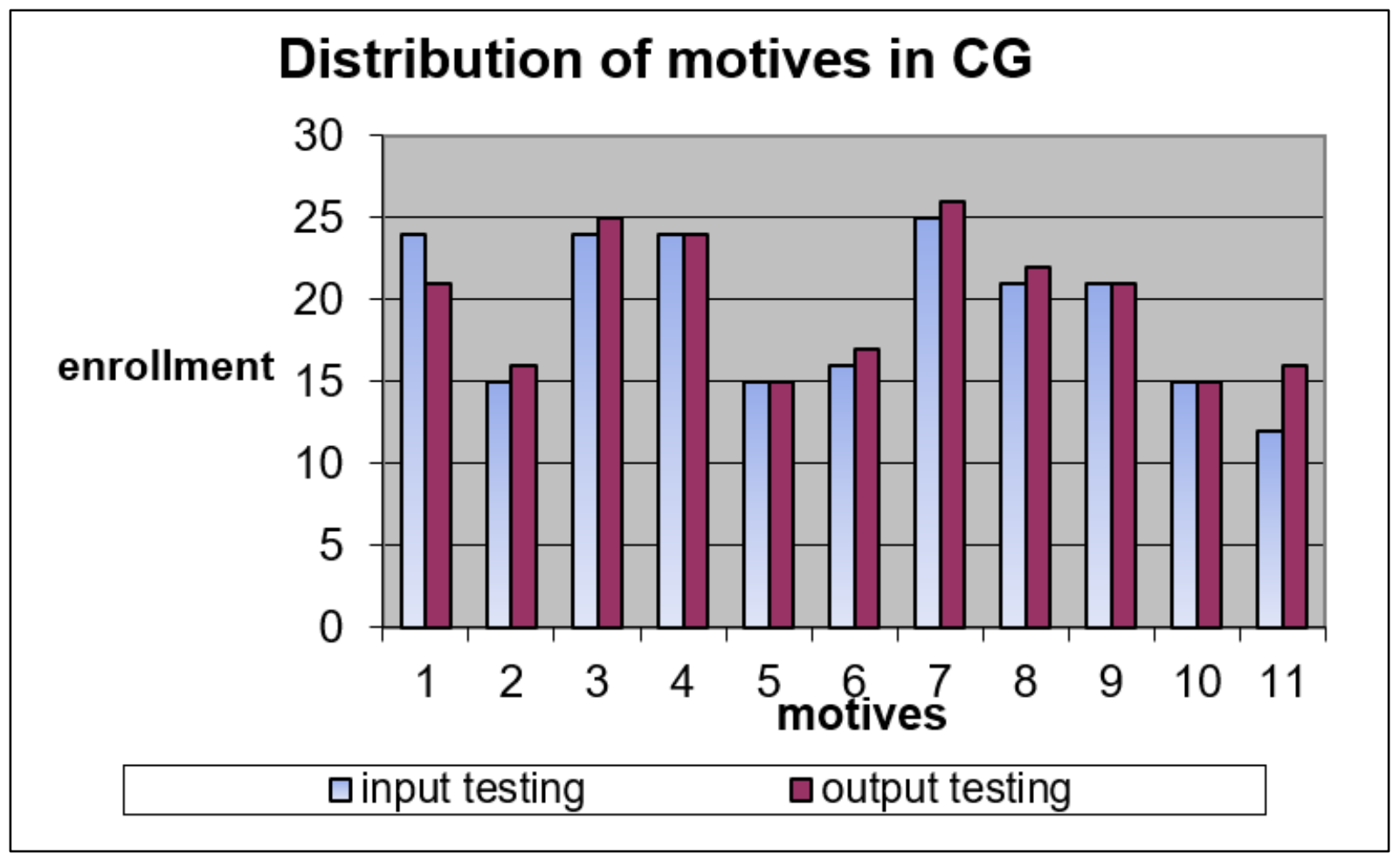

Figure 1. Distribution of motives in $\mathrm{CG}$

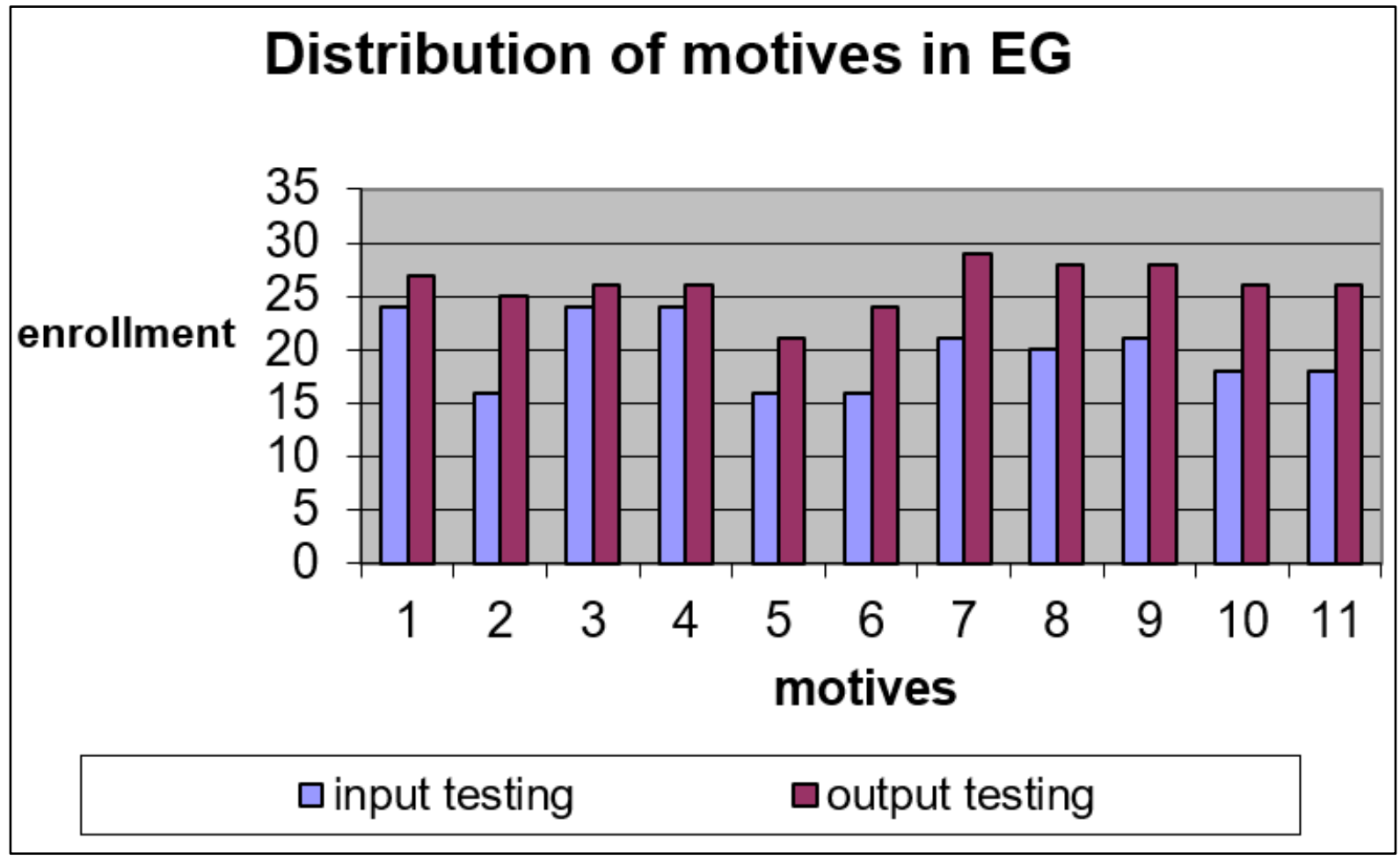

Figure 2. Distribution of motives in EG

The diagram shows that the input and output test data have sufficient differences (Figure 2). Therefore, in the EG there is a significant shift in the motivational sphere of students.

\section{Conclusions}

The average school age is of particular interest in the study of the formation of a motivational value for 
cognitive activity. This age is from 11 to 15 years of age and is a transition from childhood to adolescence. The successful development of a motivational and value-based attitude to the cognitive activities of students in school is a vital guide in the quest to develop a person ready to live in a high-tech, competitive world.

Among the pedagogical conditions affecting the development of a motivational and value-based attitude to the cognitive activities of pupils of secondary school age, the following are the most favourable:

- interactive learning through a leading activity (dialogue student, pupil, pupil, pupil);

- use of opportunities of open educational environment in free choice of forms and methods of training;

- individualizing the educational process through the use of non-formal education;

- enhancing creativity through the use of research tools and forms of non-formal education.

\section{REFERENCES}

[1] J. W. Atkinson, N. T. Feather. A theory of achievement motivation, Wiley, N.Y., 1966.

[2] D. McClelland. Human Motivation, Peter, St. Petersburg, 2007.

[3] H. Heckhausen. Psychology need for achievement, Speech,
St. Petersburg, 2001.

[4] L. Festinger. A theory of cognitive dissonance, Uwenta Publ., St. Petersburg, 1999.

[5] G. E. Shchukina. Enhancing student learning in the learning process, Moscow, 1971.

[6] A. H. Maslow. Motivation and Personality, Evraziya, St. Petersburg, 1999.

[7] A. V. Kiryakova. Values as social dominance of orientation, Letters from the Orenburg State University, Vol. 1, 18-33, 2002.

[8] S. V. Fomina. Adolescent value orientation in education, Information from the Samara Science Centre of the Russian Academy of Sciences, Vol. 3, 652-656, 2009.

[9] L. F. Il'ichev, P. N. Fedoseev, S. A. Kovalev, V. G. Panov. Encyclopedic dictionary of philosophy, Soviet Encyclopedia, Moscow, 1983.

[10] M. S. Pomelova. Interactive tools in mathematics education, Mathematics at a school, Vol. 8, 59-61, 2012.

[11] M. S. Artyukhina. Non-Formal Education: Strategic Resource of Improving Quality of Teaching Mathematics at School and University, The Social Sciences, Vol. 11, No. 25, 6112-6115, 2016.

[12] N. T. Badmaeva. Technique for diagnostics of educational motivation of schoolchildren (methodology M.V. Matyukhina in modification N.T. Badmaeva) (pp. 149-150), In: Influence of motivation factor on development of mental abilities. Monograph, VSTGU, Ulan-Ude, 2004. 